\title{
ANALISIS FAKTOR-FAKTOR YANG MEMOTIVASI MASYARAKAT BERWIRAUSAHA SEWA LAPANGAN FUTSAL DI KOTA JAMBI
}

\author{
Fadhol Adha $^{1)}$, Agus Syarif ${ }^{2)}$, Novita Sari ${ }^{3)}$ \\ ${ }^{1,2,3)}$ Prodi Manajemen FEB Universitas Jambi \\ fadholadha7@gamail.com
}

\begin{abstract}
Abstrak
Tujuan penelitian ini adalah untuk Untuk menganalisis faktor-faktor apa saja yang pengaruhi masyarakat berwirausaha usaha sewa lapangan futsal dan Untuk menjelaskan apa factor yang paling mempengaruhi masyarakat termemotivasi berwirausaha sewa apangan Futsal di Kota Jambi. Metode yang digunakan dalam penelitian adalah metode deskriptif, jenis data adalah data primer dan data sekunder, data primer diperoleh dari pelanggan sew lapangan futsal di Kota Jambi. Alat analisis yang digunakan adalah Ratarata dan modus,yang di gunakan sebagai pusat atau pemusatan data. Hasil penelitian menyimpulkan bahwa Ada beberapa faktor yang membuat masyarakat terdorong untuk melakukan wirausaha yaitu,faktor kesadaran diri,pengaturan diri,motivasi,empati dan ketrampilan sosial. Faktor motivasi di kategorikan sangat baik karena menjadi faktor yang paling mempengaruhi masyarakat untuk berwirausaha sewa lapangan futsal di Kota Jambi.
\end{abstract}

Kata Kunci : Motivasi, wirausaha

\begin{abstract}
The purpose of this study is to analyze the factors that influence the community in entrepreneurship in the futsal field rental business and to explain what factors most influence the motivated community for entrepreneurship in Futsal rental business in Jambi City. The method used in this research is descriptive method, the type of data is primary data and secondary data, primary data is obtained from customers of futsal field in Jambi City. The analysis tools used are mean and mode, which is used as the center or data center. The results of the study conclude that there are several factors that motivate people to do entrepreneurship, namely, factors of self-awareness, self-regulation, motivation, empathy and social skills. The motivational factor is categorized as very good because it is the factor that most influences the community to entrepreneurship in renting a futsal field in Jambi City.
\end{abstract}

Keywords: Motivation, entrepreneurship

\section{PENDAHULUAN}

Indonesia merupakan negara yang sedang berkembang dalam bidang perekonomiannya. Pembangunan ekonomi negara Indonesia di masa yang akan datang, sangatlah ditentukan dari peran yang maksimal dari para wirausahawannya. Para wirausahawan yang mempunyai banyak ide baru, berani berkreasi dengan produk yang dibuat, dan mampu berinovasi secara maksimal akan lebih mempercepat perkembangan ekonomi negara tersebut serta mampu memberikan sumbangsih yang besar, nyata, dan bermanfaat dalam pembangunan dan perkembangan perekonomian negara tersebut. Pertumbuhan penduduk di Indonesia dari tahun ke tahun semakin meningkat. 
Ciputra (dalam Mopangga, 2014) mengemukakan bahwa wirausaha merupakan solusi tepat untuk menyelesaikan masalah pengangguran dan kemiskinan di Indonesia, karena dengan hanya berbekal ijazah tanpa kecakapan entrepreneurship, siapkanlah diri untuk antri pekerjaan karena saat ini pasokan tenaga kerja lulusan perguruan tinggi tidak sebanding dengan peluang kerja yang tersedia.

Jelaslah bahwa kewirausahaan pada dasarnya merupakan jiwa dari seseorang yang diekspresikan melalui sikap dan perilaku yang kreatif dan inovatif untuk melakukan suatu kegiatan. Adapun orang yang memiliki jiwa tersebut tentu saja dapat melakukan kegiatan kewirausahaan atau menjadi pelaku kewirausahaan atau lebih dikenal dengan sebutan wirausaha. Peran motivasi dalam berwirausaha sangatlah penting, terutama motivasi untuk berhasil. Motivasi menurut Robbins (2001:166) adalah Kesediaan untuk mengeluarkan tingkat upaya yang tinggi untuk tujuan organisasi yang dikondisikan oleh kemampuan upaya itu untuk memenuhi beberapa kebutuhan individual.

Banyaknya pengangguran terdidik yang ada di Indonesia, haruslah disikapi oleh para mahasiswa yang masih mengenyam dunia perkuliahan karena setelah lulus dari Perguruan Tinggi, mahasiswa dihadapkan pada kondisi di mana mereka bersaing dengan para mahasiswa yang lebih dahulu lulus tetapi belum memperoleh pekerjaan. Dengan demikian, mahasiswa diharapkan untuk mampu mengubah pola pikir mereka sehingga mampu menciptakan lapangan pekerjaan baru yang mana dari kegiatan usaha yang mereka jalani mampu menyerap banyak tenaga kerja sehingga juga berperan aktif mengurangi angka pengangguran dan turut serta memberikan sumbangan terhadap perkembangan perekonomian Indonesia.

Menurut Saiman (2009) kewirausahaan adalah suatu upaya dalam penciptaan kegiatan bisnis atas dasar kemauan dan keinginan dari diri sendiri. Dengan kewirausahaan, maka dapat menciptakan lapangan pekerjaan yang luas, tidak bergantung kepada orang lain dalam mendapatkan pekerjaan dan dapat membantu pemerintah dalam mengurangi pengangguran dengan cara membuka lapangan pekerjaan.

Saiman (2009) juga menambahkan bahwa wirausaha merupakan orang-orang yang memiliki sifat-sifat kewirausahaan seperti berani mengambil risiko, pantang menyerah dan memiliki kemauan keras untuk sukses dalam mengelola bisnisnya berdasarkan kemampuan dan kemauan sendiri. Selain itu, seorang wirausaha juga memiliki penghasilan yang lebih besar dibandingkan dengan menjadi karyawan. Kewirausahaan juga dapat membantu meningkatkan pendapatan dalam negeri melalui sektor pajak.

Di saat sekarang ketika ingin mendirikan atau ingin memulai usaha masyarakat harus jeli melihat peluang,para pelaku usaha harus di tuntut menciptakan hal yang baru dan unik agar usaha mereka mampu bersaing dengan usaha-usaha lainnya. Disini peluang usaha sewa lapangan futsal merupakan salah satu ide usaha yang bagus,karena olahraga futsal telah memiliki peminat tersendiri oleh para penikmatnya.

Futsal sekarang berkembang sebagai salah satu olahraga terfavorit di Indonesia dan seiring dengan perkembangan gaya hidup sekarang, Futsal telah menjadi salah satu trend dan mulai menjadi salah satu aktivitas di kalangan masyarakat Indonesia, khususnya juga masyarakat jambi. Salah satu penyebab olahraga ini banyak digemari adalah karena minimnya open space atau lapangan sepakbola dibandingkan dengan presentase masyarakat yang hobby bermain sepakbola sehingga futsal menjadi salah satu pilihan yang tepat karena olahraga ini dimainkan di dalam ruangan dan tidak terlalu membutuhkan tempat yang luas seperti olahraga sepakbola pada umumnya.

Bisnis sewa lapangan futsal memerlukan modal yang lumayan besar apalagi tanah yang ingin kita bangun lapangan futsal tersebut bukan milik pribadi,tentu biayanya makin 
bertambah.namun demikian bisnis sewa lapangan futsal cukup menjajikan dalam hal keuntungan berbisnis,tidak hanya dari sewa lapangan saja mampu meraup keuntungan namun juga dengan menjual air minum untuk para penyewa lapangan futsal tersebut. RataRata penyewaan lapangan futsal di kota jambi adalah rata-rata sekitar 100.000 Rp-150.000 $\mathrm{Rp}$ /satu jamnya,bayangkan saja ketika lapangan futsal tersebut mampu menyewakan satu lapangan futsal sebanyak 10 jam perhari berarti lapangan futsal tersebut mampu menghasilkan 1000.000 dalam satu hari.itu baru satu lapangan futsal saja,namun jika memliki dua lapangan futsal maka jumlah keuntungan yang akan di dapat akan di bertambah dua kali lipat,belum lagi keuntungan dari hasil penjualan air minum yang terjual.

Dengan alasan tersebut sehingga masyarakat dapat terus termotivasiunntuk berbisnis usaha sewa lapangan futsal,karena sangat menjajikan untuk bersaing dalam meraup keuntungan dari usaha-usaha lainnya,selain mendapatkan keuntungan usaha sewa lapangan futsal juga membantu masyarakat jambi untuk hidup sehat dengan melakukan olahraga.

\section{Tujuan masalah}

1. Untuk menganalisis faktor-faktor apa saja yang mempengaruhi masyarakat berwirausaha usaha sewa lapangan futsal

2. Untuk menjelaskan apa faktor yang paling mempengaruhi masyarakat termemotivasi berwirausaha sewa lapangan Futsal di kota jambi.

\section{TINJAUAN PUSTAKA}

\section{Kewirausahaan}

Istilah kewirausahaan mulai dipopulerkan sejak tahun 1990.Sebelum itu istilah kewirausahaan atau enterpreneur (Bahasa Perancis) adalah lebih populer yang artinya orang membeli barang dengan harga pasti, meskipun orang itu belum tahu dengan harga berapa barang itu akan dijual. kemudian kewirausahaan dipersamakan dengan entrepreneurship artinya wirausaha diartikan berbeda-beda namun pada prinsipnya maksud dan ruang lingkupnya sama. Kewirausahaan berasal dari kata Wirausaha.Wirausaha berasal dari kata Wira artinya berani,utama, mulia.

Usaha bearti kegiatan bisnis komersil maupun non komersil. (Maseud \& Mahmud:2005) Ilmu kewirausahaan berasal dari ilmu dalam bidang perdagangan.Namun kemudian dikembangkan dalam bidang-bidang lain yakni bidang industri,pendidikan,kesehatan,lembaga pemerintah,perguruan tinggi dan lain-lain. (Suryana:2003)

Menurut Dzisi (2008) "Entrepreneurship is the result of a disciplined, systematic process of applying creativity and innovations to needs and oppurtunities in the marketplace", Jadi Kewirausahaan merupakan hasil dari proses-proses dalam penerapan kreativitas dan inovasi untuk memenuhi kebutuhan dan peluang yang di pasar. Menurut Suryana (2008), kewirausahan muncul apabila seorang individu berani mengembangkan usaha-usaha dan ide-ide barunya. Proses kewirausahaan meliputi semua fungsi, aktivitas, dan tindakan yang berhubungan dengan perolehan peluang dan penciptaan organisasi usaha.

Kewirausahaan diartikan secara harfiah sebagai hal-hal yang menyangkut keberanian seseorang untuk melakukan kegiatan bisnis maupun non bisnis secara mandiri. (Daryanto,2013:3) 


\section{Keberhasilan Usaha}

Menurut(noor,2007) Keberhasilan Usaha pada hakikatnya adalah keberhasilan dari bisnis mencapai tujuannya, suatu bisnis dikatakan berhasil bila mendapat laba, karena laba adalah tujuan dari seseorang melakukan bisnis

Menurut(ranto,2007) keberhasilan berwiraswasta tidaklah identik dengan seberapa berhasil seseorang mengumpulkan uang atau harta serta menjadi kaya, karena kekayaan bisa diperoleh dengan berbagai cara sehingga menghasilkan nilai tambah. Berusaha lebih dilihat dari bagaimana seseorang bisa membentuk, mendirikan, serta menjalankan usaha dari sesuatu yang tadinya tidak berbentuk, tidak berjalan atau mungkin tidak ada sama sekali. Seberapa pun kecilnya ukuran suatu usaha jika dimulai dari nol dan bisa berjalan dengan baik maka nilai berusahanya jelas lebih berharga daripada sebuah organisasi besar yang dimulai dengan bergelimang fasilitas.

Menurut Hutagalung (2008), sukses tidak terjadi secara kebetulan, secara instan dan tidak pula turun tiba-tiba dari langit. Sukses adalah buah dari proses sistematis, perjalanan panjang dan kerja keras. Sukses selalu diukur dengan uang, harta, jabatan, keluarga, ketenaran nama. Sukses besar berarti akumulasi dari kesemuanya.

\section{Motivasi}

Istilah motivasi (motivation) berasal dari bahasa latin, yakni movere, yang bearti "Menggerakkan" (to Move). Winardi (2002) mengatakan "Motivasi meliputi prosesproses psikologikal, yang menyebabkan timbulnya, diarahkannya, dan terjadinya persistensi kegiatan-kegiatan sukarela (volunter) yang diarahkan ke arah tujuan tertentu". Sebuah model umum tentang variabel-variabel independen yang bersifat dasar bagi motivasi kerja disajikan pada gambaar berikut : (Dunette,dkk: Winardi,2001)

Motivasi merupakan salah satu faktor penentu dalam pencapaian tujuan. Motivasi berhubungan dengan dorongan atau kekuatan yang berada dalam diri manusia. Motivasi berada dalam diri manusia yang tidak terlihat dari luar.Sikap dan motivasi memiliki hubungan yang timbal balik dan akan menunjukkan kebutuhan dalam motivasi untuk memenuhi kebutuhan karakter yang harus dimiliki seorang wirausaha yaitu pekerja keras (hard worker), tidak pernah menyerah (never surrender), memiliki semangat (spirit), memiliki komitmen (committed) yang tinggi (Endang,2012).

\section{Tipe-tipe Motivasi}

Tipe-tipe Motivasi Motivasi dapat dibedakan menjadi beberapa tipe. Motivasi dapat dibedakan menjadi dua yaitu, motivasi intrinsik dan motivasi ekstrinsik".

1) Motivasi Instrisnsik Motivasi intrinsik merupakan dorongan dari dalam diri individu yang menyebabkan individu yang bersangkutan berpartisipasi dalam suatu kegiatan. Dorongan ini sering dikatakan merupakan bawaan sejak lahir, sehingga tidak dapat dipelajari. Menurut Basrowi (2014: 17) faktor-faktor yang mempengaruhi motivasi instrinsik yaitu:

a) Kebutuhan (need) Seseorang melaksanakan aktivitas (kegiatan) karena adanya faktorfaktor kebutuhan baik biologis maupun psikologis.

b) Harapan (expectancy) Seseorang dimotivasi karena adanya harapan keberhasilan yang bersifat pemuasan diri seseorang, keberhasilan dan harga diri meningkat dan menggerakkan seseorang kearah pencapaian tujuan.

c) Minat Minat adalah suatu rasa lebih suka dan rasa keinginan pada suatu hal tanpa ada yang menyuruh atau kegiatan yang sering dilakukan setiap hari karena kegiatan tersebut disukainya. 
2) Motivasi Ekstrisnsik Motivasi ekstrinsik adalah dorongan dari luar individu yang menyebabkan individu berpartisipasi dalam kegiatan. Menurut Basrowi (2014: 19), faktorfaktor yang mempengaruhi motivasi ekstrinsik yaitu:

a) Dorongan Keluarga Keluarga adalah sebuah kelompok yang terdiri dari dua orang atau lebih yang masing-masing mempunyai hubungan kekerabatan yang terdiri dari bapak, ibu, kakek, nenek.

b) Lingkungan Lingkungan adalah tempat dimana orang tinggal. Lingkungan dapat mempengaruhi seseorang sehingga dapat termotivasi untuk melakukan sesuatu. Selain keluarga lingkungan juga mempunyai peran yang besar dalam memotivasi seseorang dalam merubah tingkah lakunya.

c) Imbalan Seseorang dapat termotivasi karena adanya imbalan sehingga orang tersebut ingin melakukan sesuatu.

\section{Motivasi Berwirausaha}

Pengertian Motivasi Berwirausaha Motivasi berwirausaha tidak dibawa sejak lahir, tetapi suatu proses yang dipelajari, dilatih, ditingkatkan dan dikembangkan. Motivasi berwirausaha merupakan suatu keadaan yang timbul dalam diri seseorang untuk mengambil tindakan atau mencapai tujuan dalam bidang kewirausahaan. Menurut Leonardus Saiman (2009: 26) mengemukakan empat motivasi seseorang untuk berwirausaha, yaitu sebagai berikut:

a) Laba Dapat menentukan berapa laba yang dikehendaki, keuntungan yang diterima, dan berapa yang akan dibayarkan kepada pihak lain atau pegawainya.

b) Kebebasan Bebas mengatur waktu, bebas dari supervisor, bebas dari aturan yang menekan, dan bebas dari budaya organisasi/perusahaan.

c) Impian Personal Bebas mencapai standar hidup yang diharapkan, lepas dari rutinitas kerja yang berulang-ulang, karena harus mengikuti visi, misi, impian orang lain.

d) Kemandirian Memiliki rasa bangga, karena dapat mandiri dalam segala hal, seperti permodalan, mandiri dalam pengelolaan atau manajemen, mandiri dalam pengawasan, serta menjadi manajer terhadap dirinya sendiri.

\section{Teori Motivasi Berwirausaha Motivasi}

Teori Motivasi Berwirausaha Motivasi merupakan proses psikologis yang mendasar, dan merupakan salah satu unsur yang dapat menjelaskan perilaku seseorang. Motivasi merupakan salah satu faktor penentu dalam pencapaian tujuan. Hal ini sesuai dengan pendapat Abu Ahmadi (Yuyus Suryana dan Kartib Bayu, 2013: 98) motivasi merupakan dorongan yang telah terikat pada suatu tujuan. Motif timbul karena adanya kebutuhan. Kebutuhan dipandang sebagai kekurangan adanya sesuatu dan ini menuntut segera pemenuhannya, untuk segera mendapat keseimbangan. Situasi kekurangan ini berfungsi sebagai suatu kekuatan atau dorongan yang menyebabkan seseorang bertindak untuk memenuhi kebutuhannya, banyak teori untuk memahami motivasi berwirausaha

\section{Faktor-Faktor Pendorong Minat Berwirausaha}

Menurut Kuncara (2008:1) faktor pendorong kewirausahaan terdiri atas faktor internal dan faktor eksternal sebagai berikut:

Faktor internal, yaitu kecakapan pribadi yang menyangkut soal bagaimana kita mengelola diri sendiri. Kecakapan pribadi seseorang terdiri atas 3 unsur terpenting, yaitu: (1) Kesadaran diri. Ini menyangkut kemampuan mengenali emosi diri sendiri dan efeknya, mengetahui kekuatan dan batas-batas diri sendiri, dan keyakinan tentang harga diri dan 
kemampuan sendiri atau percaya diri. (2) Pengaturan diri. Ini menyangkut kemampuan mengelola emosi-emosi dan desakan-desakan yang merusak, memelihara norma kejujuran dan integritas, bertanggung jawab atas kinerja pribadi, keluwesan dalam menghadapi perubahan, dan mudah menerima atau terbuka terhadap gagasan, pendekatan dan informasi-informasi baru. (3) Motivasi. Ini menyangkut dorongan prestasi untuk menjadi lebih baik, komitmen, inisiatif untuk memanfaatkan kesempatan, dan optimisme dalam menghadapi halangan dan kegagalan.

Faktor eksternal, yaitu kecakapan sosial yang menyangkut soal bagaimana kita menangani suatu hubungan. kecakapan sosial seseorang terdiri atas 2 unsur terpenting, yaitu: (1) Empati. Ini menyangkut kemampuan untuk memahami orang lain, perspektif orang lain, dan berminat terhadap kepentingan orang lain. Juga kemampuan mengantisipasi, mengenali, dan berusaha memenuhi kebutuhan pelanggan. Mengatasi keragaman dalam membina pergaulan, mengembangkan orang lain, dan kemampuan membaca arus-arus emosi sebuah kelompok dan hubungannya dengan kekuasaan, juga tercakup didalamnya. (2) Keterampilan sosial.

\section{METODE PENELITIAN}

\section{Jenis dan Sumber data}

a. Data primer

Data primer merupakan data yang diperoleh oleh penyebaran kuesioner kepada beberapa pemilik usaha sewa lapangan futsal di kota jambi.

b. Data sekunder

Data sekunder dalam penelitian ini diperoleh dari berbagai bahan pustaka baik berupa buku-buku, jurnal, data-data elektronik yang diambil dari internet, dan dokumendokumen pendukung lainnya yang berkaitan dengan usaha sewa lapangan futsal di Kota Jambi

\section{Populasi}

Populasi (Sugiyono:2012) adalah wilayah generalisasi yang terdiri atas: Obyek/subyek yang mempunyai kualitas dan karakteristik tertentu yang ditetapkan oleh peneliti untuk dipelajari dan kemudian di tarik kesimpulannya. Populasi dalam penelitian ini adalah usaha sewa lapangan futsal yang ada di sekitar Kota Jambi yang berjumlah 30 buah.

\section{Sampel}

Sample dalam penelitian ini adalah pemilik usaha sewa lapangan futsal di kota jambi yang usaha sewa lapangan futsalnya masih berjalan. Mengingat penelitian ini jumlah populasinya tidak terlalu banyak yakni hanya 30 usaha maka teknik pengambilan sampel yang digunakan adalah sampel total, jadi seluruh obyek dalam populasi di jadikan sampel.

\section{Metode Pengumpulan Data}

Metode pengumpulan data yang digunakan dalam penelitian ini adalah :

\section{Penelitian Kepustakaan}

Penelitian ini dilakukan dengan cara mempelajari buku-buku (literature) dan penelitian terdahulu dengan pemilihan teori-teori yang ada hubungannya dengan masalah yang akan dibahas. Cara ini dilakukan untuk memperoleh data yang sekunder yang menjadi landasan teori guna mendukung data yang diperoleh dalam penelitian. 


\section{Penelitian Lapangan}

Dalam suatu penelitian ilmiah, metode pengumpulan data dimaksudkan untuk memperoleh bahan-bahan yang relevan, akurat, dan terpercaya (Indrianto dan Supomo, 2003). Dalam penelitian ini pengumpulan data menggunakan kuesioner atau dikenal juga dengan sebutan angket. Kuesioner merupakan teknik pengumpulan data yang dilakukan dengan cara memberi seperangkat pertanyaan tertulis kepada responden untuk diisi. gunanya untuk mengetahui apakah faktor-faktor tersebut berlaku pada konsumen usaha sewa lapangan futsal di kota jambi Kota Jambi.

\section{Sumber Data}

Data yang di peroleh dalam penelitian ini adalah dari para pemilik usaha sewa lapangan futsal di kota jambi yaitu sebanyak 30 orang (responden). Kemudian data yang lain di peroleh dari buku, internet,dan artikel-artikel lainnya yang berhubungan dengan motivasi dan berwirausaha.

\section{Metode Analisis}

Metode deskriptif adalah salah satu metode yang berfungsi untuk mendeskripsikan atau memberi gambaran terhadap objek yang diteliti melalui data atau sampel yang telah terkumpul sebagaimana adanya tanpa melakukan analisis dan membuat kesimpulan yang berlaku untuk umum. Sugiono (2009 : 29)

Metode analisis deskriptif merupakan cara menguraikan dan menafsirkan data yang ada sehingga memberikan gambaran yang jelas mengenai permasalahan.analisis deskriptif dilakukan peneliti yaitu dengan mendistribusikan dalam bentuk tabel sehingga memperoleh gambaran yang jelas tentang distribusi jawaban responden. Kemudian penelitian ini menggunakan Analisis kualitatif,analisis kualitatif adalah metode yang memberikan informasi yang mutakhir sehingga bermanfaat bagi perkembangan ilmu pengetahuan serta lebih banyak dapat di terapkan pada berbagai masalah (husein umar, 2005) dan didasarkan pada ruang lingkup pembahasan statistic deskriptif yang akan di bahas dalam penelitian ini mencakup :

1. Rata-rata dan modus,yang di gunakan sebagai pusat atau pemusatan data

a. Rata-rata,yaitu jumlah data dibagi banyaknya data

$$
\text { Rumus : Rata-rata }=\frac{\text { Jumlah data }}{\text { Banyak data }}
$$

b. modus yaitu,nilai atau data yang paling sering keluar/muncul.

2. Standar deviasi,merupakan salah satu ukuran sebaran yang paling sering di gunakan dalam berbagai analisis statistika.

Rumus standard deviasi itu adalah akar dari variasi,standard deviasi sering di lambangkan dengan symbol $\sigma$,sedangkan variasi di simbol dengan $\sigma^{2}$

Rumus : $\sigma=\sqrt{ } \sigma^{2}$

\section{HASIL DAN PEMBAHASAN \\ Hasil Penelitian}

Dari 30 responden yang di berikan pernyataan yang di sebarkan dalam bentuk kuisioner kepada pemilik usaha sewa lapangan futsal di kota jambi didapat hasil penelitian sebagai berikut : 


\section{Faktor Internal}

\section{Kesadaran diri}

Tabel 1. Deskriptif Dimensi Kesadaran Diri Pernyataan 1

\begin{tabular}{|c|c|c|c|c|c|c|c|c|c|c|c|}
\hline \multirow[t]{2}{*}{ Dimensi kesadaran diri } & \multirow{4}{*}{$\begin{array}{l}\text { Jumlah } \\
\text { responden }\end{array}$} & \multicolumn{10}{|c|}{ Frekuensi jawaban responden } \\
\hline & & \multicolumn{2}{|l|}{ SS } & \multicolumn{2}{|l|}{$\mathrm{s}$} & \multicolumn{2}{|l|}{ ks } & \multicolumn{2}{|l|}{ ts } & \multicolumn{2}{|l|}{ Sts } \\
\hline \multirow[t]{2}{*}{ indikator } & & \multicolumn{2}{|l|}{5} & \multicolumn{2}{|l|}{4} & \multicolumn{2}{|l|}{3} & \multicolumn{2}{|l|}{2} & \multicolumn{2}{|l|}{1} \\
\hline & & jml & $\%$ & jml & $\%$ & $\mathrm{jml}$ & $\%$ & $\mathrm{jml}$ & $\%$ & $\mathrm{jml}$ & $\%$ \\
\hline $\begin{array}{l}\text { Saya tahu kelebihan dan } \\
\text { kekurangan saya dalam } \\
\text { berwirausaha }\end{array}$ & 30 & 8 & 26,6 & 12 & 40 & 10 & 33,3 & 0 & 0 & 0 & 0 \\
\hline \multirow[t]{4}{*}{ jumlah } & Rata-rata & \multicolumn{10}{|l|}{3,9} \\
\hline & SD & \multicolumn{10}{|c|}{0,75} \\
\hline & modus & \multicolumn{10}{|l|}{4} \\
\hline & skor & \multicolumn{10}{|c|}{117} \\
\hline
\end{tabular}

Dari tabel diatas terlihat dimensi kesadaran diri dengan pernyataan saya tahu kelebihan dan kekurangan saya dalam berwirausaha memiliki rata-rata 3,9 dengan angka modus 4 dan standard deviasi 0,75. Dengan skor 117 hal ini menggambarkan bahwa dimensi kesadaran diri pada responden di kategorikan Baik.

Tabel 2. Deskriptif Dimensi Kesadaran Diri Pernyataan 2

\begin{tabular}{|c|c|c|c|c|c|c|c|c|c|c|c|}
\hline \multirow[t]{2}{*}{ Dimensi kesadaran diri } & \multirow{4}{*}{\begin{tabular}{|l|} 
Jumlah \\
responden
\end{tabular}} & \multicolumn{10}{|c|}{ Frekuensi jawaban responden } \\
\hline & & \multirow{2}{*}{\multicolumn{2}{|c|}{$\begin{array}{l}\text { SS } \\
5\end{array}$}} & \multirow{2}{*}{\multicolumn{2}{|c|}{$\frac{\mathrm{s}}{4}$}} & \multicolumn{2}{|l|}{ Ks } & \multirow{2}{*}{\multicolumn{2}{|c|}{\begin{tabular}{|l|} 
ts \\
2 \\
\end{tabular}}} & \multicolumn{2}{|l|}{ sts } \\
\hline \multirow{2}{*}{ indikator } & & & & & & 3 & & & & & \\
\hline & & jml & $\%$ & $\mathrm{jml}$ & $\%$ & $\mathrm{jml}$ & $\%$ & $\mathrm{jml}$ & $\%$ & $\mathrm{jml}$ & $\%$ \\
\hline $\begin{array}{l}\text { Saya yakin usaha sewa } \\
\text { lapangan futsal akan berbuah } \\
\text { manis saya dan keluarga }\end{array}$ & 30 & 7 & 23,3 & 18 & 60 & 5 & 16,6 & 0 & 0 & 0 & 0 \\
\hline \multirow[t]{4}{*}{ jumlah } & Rata-rata & \multicolumn{10}{|c|}{4,06} \\
\hline & SD & \multicolumn{10}{|c|}{0,63} \\
\hline & modus & \multicolumn{10}{|c|}{4} \\
\hline & skor & \multicolumn{10}{|l|}{122} \\
\hline
\end{tabular}

Sumber: Data primer yang diolah tahun 2019

Dari tabel diatas terlihat dimensi kesadaran diri dengan indikator Saya yakin usaha sewa lapangan futsal akan berbuah manis saya dan keluarga memiliki rata-rata 4,06 dengan angka modus 4 dan standard deviasi 0,63. Dengan skor 122 Hal ini menggambarkan bahwa dimensi kesadaran diri pada responden di kategorikan Sangat Baik.

Tabel 3. Deskriptif Dimensi Kesadaran Diri Pernyataan 3

\begin{tabular}{|c|c|c|c|c|c|c|c|c|c|c|c|}
\hline \multirow[t]{2}{*}{ Dimensi kesadaran diri } & \multirow{4}{*}{$\begin{array}{l}\text { Jumlah } \\
\text { responde } \\
\mathrm{n}\end{array}$} & \multicolumn{10}{|c|}{ Frekuensi jawaban responden } \\
\hline & & \multicolumn{2}{|l|}{ ss } & \multicolumn{2}{|l|}{$\mathrm{S}$} & \multicolumn{2}{|l|}{ ks } & \multicolumn{2}{|l|}{ ts } & \multicolumn{2}{|l|}{ sts } \\
\hline \multirow[t]{2}{*}{ indikator } & & \multicolumn{2}{|l|}{5} & \multicolumn{2}{|l|}{4} & \multicolumn{2}{|l|}{3} & \multicolumn{2}{|l|}{2} & \multicolumn{2}{|l|}{1} \\
\hline & & $\mathrm{jml}$ & $\%$ & $\mathrm{jml}$ & $\%$ & jml & $\%$ & jml & $\%$ & jm & $\%$ \\
\hline $\begin{array}{l}\text { Saya mendirikan sewa } \\
\text { lapangan futsal karena futsal } \\
\text { adalah hobby saya }\end{array}$ & 30 & 4 & 23,3 & 10 & 33,3 & 14 & 46,6 & 2 & 6,6 & 0 & 0 \\
\hline \multirow[t]{4}{*}{ jumlah } & Rata-rata & \multicolumn{10}{|c|}{3,53} \\
\hline & SD & \multicolumn{10}{|c|}{0,81} \\
\hline & modus & \multicolumn{10}{|l|}{3} \\
\hline & Skor & \multicolumn{10}{|c|}{106} \\
\hline
\end{tabular}

Sumber: Data primer yang diolah tahun 2019 
Dari tabel diatas terlihat dimensi kesadaran diri dengan indikator Saya mendirikan sewa lapangan futsal karena futsal adalah hobby saya memiliki rata-rata 3,53 dengan angka modus 3 dan standard deviasi 0,81. Dengan skor 106 Hal ini menggambarkan bahwa dimensi kesadaran diri pada responden di kategorikan Baik.

\section{Pengaturan diri}

Tabel 4. Deskriptif Pengaturan Diri Pernyataan 1

\begin{tabular}{|c|c|c|c|c|c|c|c|c|c|c|c|}
\hline \multirow{4}{*}{$\begin{array}{l}\text { Dimensi pengaturan diri } \\
\text { indikator }\end{array}$} & \multirow{4}{*}{$\begin{array}{l}\text { Jumlah } \\
\text { responden }\end{array}$} & \multicolumn{10}{|c|}{ Frekuensi jawaban responden } \\
\hline & & \multicolumn{2}{|c|}{ Ss } & \multirow{2}{*}{\multicolumn{2}{|c|}{$\frac{\mathrm{s}}{4}$}} & \multirow{2}{*}{\multicolumn{2}{|c|}{$\frac{\mathrm{ks}}{3}$}} & \multirow{2}{*}{\multicolumn{2}{|c|}{$\frac{\text { Ts }}{2}$}} & \multirow{2}{*}{\multicolumn{2}{|c|}{$\begin{array}{l}\text { sts } \\
1\end{array}$}} \\
\hline & & \multicolumn{2}{|l|}{5} & & & & & & & & \\
\hline & & jml & $\%$ & jml & $\%$ & jml & $\%$ & Jml & $\%$ & jml & $\%$ \\
\hline $\begin{array}{l}\text { Keputusan yang saya ambil } \\
\text { untuk memulai usaha sewa } \\
\text { lapangan futsal adalah } \\
\text { pertimbangan yang matang }\end{array}$ & 30 & 4 & 13,3 & 19 & 63,3 & 7 & 23,3 & 0 & 0 & 0 & 0 \\
\hline \multirow[t]{4}{*}{ jumlah } & Rata-rata & \multicolumn{10}{|c|}{3,86} \\
\hline & SD & \multicolumn{10}{|c|}{0,62} \\
\hline & modus & \multicolumn{10}{|l|}{4} \\
\hline & skor & \multicolumn{10}{|c|}{116} \\
\hline
\end{tabular}

Sumber: Data primer yang diolah tahun 2019

Dari tabel diatas terlihat dimensi pengataturan diri dengan indikator Keputusan yang saya ambil untuk memulai usaha sewa lapangan futsal adalah pertimbangan yang matang memiliki rata-rata 3,86 dengan angka modus 4 dan standard deviasi 0,62. Dengan skor 116 Hal ini menggambarkan bahwa dimensi kesadaran diri pada responden di kategorikan Baik.

Tabel 5. Deskriptif Pengaturan Diri Pernyataan 2

\begin{tabular}{|c|c|c|c|c|c|c|c|c|c|c|c|}
\hline \multirow{4}{*}{$\begin{array}{l}\text { Dimensi pengaturan diri } \\
\text { indikator }\end{array}$} & \multirow{4}{*}{$\begin{array}{l}\text { Jumlah } \\
\text { responden }\end{array}$} & \multicolumn{10}{|c|}{ Frekuensi jawaban responden } \\
\hline & & \multicolumn{2}{|l|}{ SS } & \multirow{2}{*}{\multicolumn{2}{|c|}{$\begin{array}{l}\mathrm{s} \\
4\end{array}$}} & \multicolumn{2}{|l|}{ ks } & \multicolumn{2}{|l|}{ Ts } & \multicolumn{2}{|l|}{ sts } \\
\hline & & \multicolumn{2}{|l|}{5} & & & \multicolumn{2}{|l|}{3} & \multicolumn{2}{|l|}{2} & \multicolumn{2}{|l|}{1} \\
\hline & & jml & $\%$ & $\mathrm{jml}$ & $\%$ & $\mathrm{jml}$ & $\%$ & jml & $\%$ & $\mathrm{jml}$ & $\%$ \\
\hline $\begin{array}{l}\text { Saya mau bekerja keras demi } \\
\text { kemajuan usaha sewa } \\
\text { lapangan futsal saya }\end{array}$ & 30 & 4 & 13,3 & 15 & 50 & 11 & 36,6 & 0 & 0 & 0 & 0 \\
\hline \multirow[t]{4}{*}{ jumlah } & Rata-rata & \multicolumn{10}{|l|}{3,7} \\
\hline & SD & \multicolumn{10}{|c|}{0,65} \\
\hline & modus & \multicolumn{10}{|l|}{4} \\
\hline & skor & \multicolumn{10}{|l|}{111} \\
\hline
\end{tabular}

Sumber: Data primer yang diolah tahun 2019

Dari tabel diatas terlihat dimensi pengaturan diri dengan indikator Saya mau bekerja keras demi kemajuan usaha sewa lapangan futsal saya memiliki rata-rata 3,7 dengan angka modus 4 dan standard deviasi 0,65. Dengan skor 111 Hal ini menggambarkan bahwa dimensi kesadaran diri pada responden di kategorikan Baik. 
Tabel 6. Deskriptif Pengaturan Diri Pernyataan 3

\begin{tabular}{|c|c|c|c|c|c|c|c|c|c|c|c|}
\hline \multirow[t]{2}{*}{ Dimensi pengaturan diri } & \multirow{4}{*}{$\begin{array}{l}\text { Jumlah } \\
\text { responden }\end{array}$} & \multicolumn{10}{|c|}{ Frekuensi jawaban responden } \\
\hline & & \multicolumn{2}{|l|}{ SS } & \multicolumn{2}{|l|}{$\mathrm{S}$} & \multicolumn{2}{|l|}{ ks } & \multicolumn{2}{|l|}{ ts } & \multicolumn{2}{|l|}{ sts } \\
\hline \multirow[t]{2}{*}{ indikator } & & \multicolumn{2}{|l|}{5} & \multicolumn{2}{|l|}{4} & \multicolumn{2}{|l|}{3} & \multicolumn{2}{|l|}{2} & \multicolumn{2}{|l|}{1} \\
\hline & & jml & $\%$ & $\mathrm{jml}$ & $\%$ & $\mathrm{jml}$ & $\%$ & $\mathrm{jml}$ & $\%$ & $\mathrm{jml}$ & $\%$ \\
\hline $\begin{array}{l}\text { Saya berusaha } \\
\text { mempersiapkan diri untuk } \\
\text { menghadapi segala } \\
\text { kemungkinan terjadi }\end{array}$ & 30 & 2 & 6,6 & 9 & 30 & 19 & 63,3 & 0 & 0 & 0 & 0 \\
\hline \multirow[t]{4}{*}{ jumlah } & Rata-rata & \multicolumn{10}{|c|}{3,43} \\
\hline & SD & \multicolumn{10}{|c|}{0,62} \\
\hline & modus & \multicolumn{10}{|l|}{3} \\
\hline & skor & \multicolumn{10}{|l|}{103} \\
\hline
\end{tabular}

Sumber: Data primer yang diolah tahun 2019

Dari tabel diatas terlihat dimensi pengaturan diri dengan indikator Saya berusaha mempersiapkan diri untuk menghadapi kemungkinan terjadi terhadap usaha sewa lapanngan futsal saya memiliki rata-rata 3,43 dengan angka modus 3 dan standard deviasi 0,62. Dengan skor $103 \mathrm{Hal}$ ini menggambarkan bahwa dimensi kesadaran diri pada responden di kategorikan Baik.

\section{Motivasi}

\begin{tabular}{|c|c|c|c|c|c|c|c|c|c|c|c|}
\hline \multirow{4}{*}{$\begin{array}{l}\text { Dimensi motivasi } \\
\text { indikator }\end{array}$} & \multirow{4}{*}{$\begin{array}{l}\text { Jumlah } \\
\text { responden }\end{array}$} & \multicolumn{10}{|c|}{ Frekuensi jawaban responden } \\
\hline & & \multicolumn{2}{|c|}{ ss } & \multirow{2}{*}{\multicolumn{2}{|c|}{$\frac{\mathrm{s}}{4}$}} & \multicolumn{2}{|l|}{$\mathrm{Ks}$} & \multirow{2}{*}{\multicolumn{2}{|c|}{ ts }} & \multirow{2}{*}{\multicolumn{2}{|c|}{ sts }} \\
\hline & & \multicolumn{2}{|l|}{5} & & & \multicolumn{2}{|l|}{3} & & 2 & & \\
\hline & & $\mathrm{jml}$ & $\%$ & jml & $\%$ & $\mathrm{Jml}$ & $\%$ & $\mathrm{jml}$ & $\%$ & $\mathrm{jml}$ & $\%$ \\
\hline $\begin{array}{l}\text { Keluarga saya mendukung } \\
\text { penuh usaha yang saya dirikan }\end{array}$ & 30 & 8 & 26,6 & 18 & 60 & 4 & 13,3 & 0 & 0 & 0 & 0 \\
\hline \multirow[t]{4}{*}{ jumlah } & Rata-rata & \multicolumn{10}{|l|}{4,06} \\
\hline & $\mathrm{SD}$ & \multicolumn{10}{|c|}{0,63} \\
\hline & modus & \multicolumn{10}{|l|}{4} \\
\hline & Skor & \multicolumn{10}{|l|}{122} \\
\hline
\end{tabular}

Sumber: Data primer yang diolah tahun 2019

Dari tabel diatas terlihat dimensi motivasi dengan indikator Keluarga saya mendukung penuh usaha yang saya dirikan memiliki rata-rata 4,06 dengan angka modus 4 dan standard deviasi 0,63. Dengan skor $122 \mathrm{Hal}$ ini menggambarkan bahwa dimensi kesadaran diri pada responden di kategorikan Sangat Baik.

Tabel 8. Deskriptif Tabel Motivasi Pernyataan 2

\begin{tabular}{|c|c|c|c|c|c|c|c|c|c|c|c|}
\hline \multirow{4}{*}{$\begin{array}{l}\text { Dimensi motivasi } \\
\text { indikator }\end{array}$} & \multirow{4}{*}{$\begin{array}{l}\text { Jumlah } \\
\text { responden }\end{array}$} & \multicolumn{10}{|c|}{ Frekuensi jawaban responden } \\
\hline & & \multicolumn{2}{|l|}{ ss } & \multirow{2}{*}{\multicolumn{2}{|c|}{$\begin{array}{l}\mathrm{s} \\
4\end{array}$}} & \multicolumn{2}{|c|}{$\mathrm{ks}$} & \multirow{2}{*}{\multicolumn{2}{|c|}{$\frac{\text { ts }}{2}$}} & \multicolumn{2}{|l|}{ sts } \\
\hline & & \multicolumn{2}{|l|}{5} & & & \multicolumn{2}{|l|}{3} & & & \\
\hline & & $\mathrm{jml}$ & $\%$ & jml & $\%$ & $\mathrm{jml}$ & $\%$ & $\mathrm{jml}$ & $\%$ & $\mathrm{jml}$ & $\%$ \\
\hline $\begin{array}{l}\text { Dengan berwirausaha usaha } \\
\text { sewa lapangan futsal saya } \\
\text { akan mendapat keuntungan }\end{array}$ & 30 & 7 & 23,3 & 23 & 76,6 & 0 & 0 & 0 & 0 & 0 & 0 \\
\hline \multirow[t]{4}{*}{ jumlah } & Rata-rata & \multicolumn{10}{|c|}{4,23} \\
\hline & SD & \multicolumn{10}{|c|}{0,43} \\
\hline & modus & \multicolumn{10}{|c|}{4} \\
\hline & skor & \multicolumn{10}{|c|}{127} \\
\hline
\end{tabular}

Sumber: Data primer yang diolah tahun 2019 
Dari tabel diatas terlihat dimensi motivasi dengan indikator Dengan berwirausaha usaha sewa lapangan futsal saya akan mendapat keuntungan memiliki rata-rata 4,23 dengan angka modus 4 dan standard deviasi 0,43. Dengan skor $127 \mathrm{Hal}$ ini menggambarkan bahwa dimensi kesadaran diri pada responden di kategorikan Sangat Baik.

Tabel 9. Deskriptif Tabel Motivasi Pernyataan 2

\begin{tabular}{|c|c|c|c|c|c|c|c|c|c|c|c|}
\hline \multirow[t]{2}{*}{ Dimensi motivasi } & \multirow{4}{*}{$\begin{array}{l}\text { Jumlah } \\
\text { responden }\end{array}$} & \multicolumn{10}{|c|}{ Frekuensi jawaban responden } \\
\hline & & \multicolumn{2}{|l|}{ SS } & \multicolumn{2}{|l|}{$\mathrm{s}$} & \multicolumn{2}{|l|}{ ks } & \multicolumn{2}{|l|}{ ts } & \multicolumn{2}{|l|}{ sts } \\
\hline \multirow[t]{2}{*}{ indikator } & & \multicolumn{2}{|l|}{5} & \multicolumn{2}{|l|}{4} & \multicolumn{2}{|l|}{3} & \multicolumn{2}{|l|}{2} & \multicolumn{2}{|l|}{1} \\
\hline & & $\mathrm{jml}$ & $\%$ & $\mathrm{jml}$ & $\%$ & $\mathrm{jml}$ & $\%$ & $\mathrm{jml}$ & $\%$ & jml & $\%$ \\
\hline \multirow{2}{*}{$\begin{array}{l}\text { Saya yakin jumlah konsumen } \\
\text { sewa futsal di jambi cukup } \\
\text { banyak }\end{array}$} & 30 & 16 & 53,3 & 13 & 43,3 & 1 & 3,3 & 0 & 0 & 0 & 0 \\
\hline & Rata-rata & \multicolumn{10}{|l|}{4,5} \\
\hline \multirow{3}{*}{ Jumlah } & SD & \multicolumn{10}{|c|}{0,57} \\
\hline & modus & \multicolumn{10}{|l|}{5} \\
\hline & skor & \multicolumn{10}{|c|}{135} \\
\hline
\end{tabular}

Sumber: Data primer yang diolah tahun 2019

Dari tabel diatas terlihat dimensi motivasi dengan indikator Saya yakin jumlah konsumen sewa futsal di jambi cukup banyak memiliki rata-rata 4,5 dengan angka modus 5 dan standard deviasi 0,57. Dengan skor 135 Hal ini menggambarkan bahwa dimensi kesadaran diri pada responden di kategorikan Sangat Baik.

\section{Faktor eksternal}

\section{Empati}

\begin{tabular}{|c|c|c|c|c|c|c|c|c|c|c|c|}
\hline \multirow{4}{*}{$\begin{array}{l}\text { Dimensi empati } \\
\text { indikator }\end{array}$} & \multirow{4}{*}{$\begin{array}{l}\text { Jumlah } \\
\text { responden }\end{array}$} & \multicolumn{10}{|c|}{ Frekuensi jawaban responden } \\
\hline & & \multirow{2}{*}{\multicolumn{2}{|c|}{$\begin{array}{l}\text { SS } \\
5\end{array}$}} & \multirow{2}{*}{\multicolumn{2}{|c|}{$\frac{s}{4}$}} & \multirow{2}{*}{\multicolumn{2}{|c|}{$\begin{array}{l}\mathrm{ks} \\
3\end{array}$}} & \multirow{2}{*}{\multicolumn{2}{|c|}{$\frac{\text { ts }}{2}$}} & \multirow{2}{*}{\multicolumn{2}{|c|}{$\frac{\text { sts }}{1}$}} \\
\hline & & & & & & & & & & & \\
\hline & & $\mathrm{jml}$ & $\%$ & jml & $\%$ & $\overline{\mathrm{jml}}$ & $\%$ & jml & $\%$ & jml & $\%$ \\
\hline $\begin{array}{l}\text { Saya senang melihat } \\
\text { konsumen bermain dilapangan } \\
\text { usaha sewa lapangan fustal }\end{array}$ & 30 & 4 & 13,3 & 18 & 60 & 8 & 26,6 & 0 & 0 & 0 & 0 \\
\hline \multirow[t]{4}{*}{ jumlah } & Rata-rata & \multicolumn{10}{|c|}{3,86} \\
\hline & $\mathrm{SD}$ & \multicolumn{10}{|c|}{0,62} \\
\hline & modus & \multicolumn{10}{|c|}{4} \\
\hline & skor & \multicolumn{10}{|c|}{116} \\
\hline
\end{tabular}

Sumber: Data primer yang diolah tahun 2019

Dari tabel diatas terlihat dimensi empati dengan indikator Saya senang melihat konsumen bermain di lapangan usaha sewa lapangan fustal saya memiliki rata-rata 3,86 dengan angka modus 4 dan standard deviasi 0,62. Dengan skor 116 Hal ini menggambarkan bahwa dimensi kesadaran diri pada responden di kategorikan Baik. 
Tabel 11. Deskriptif Empati Pernyataan 2

\begin{tabular}{|c|c|c|c|c|c|c|c|c|c|c|c|}
\hline \multirow{4}{*}{$\begin{array}{l}\text { Dimensi empati } \\
\text { indikator }\end{array}$} & \multirow{4}{*}{$\begin{array}{l}\text { Jumlah } \\
\text { responden }\end{array}$} & \multicolumn{10}{|c|}{ Frekuensi jawaban responden } \\
\hline & & \multirow{2}{*}{\multicolumn{2}{|c|}{$\begin{array}{l}\text { Ss } \\
5\end{array}$}} & \multirow{2}{*}{\multicolumn{2}{|c|}{$\frac{s}{4}$}} & \multirow{2}{*}{\multicolumn{2}{|c|}{$\begin{array}{l}\mathrm{ks} \\
3\end{array}$}} & \multirow{2}{*}{\multicolumn{2}{|c|}{$\frac{\mathrm{ts}}{2}$}} & \multirow{2}{*}{\multicolumn{2}{|c|}{$\begin{array}{l}\text { sts } \\
1\end{array}$}} \\
\hline & & & & & & & & & & & \\
\hline & & jml & $\%$ & $\mathrm{jml}$ & $\%$ & $\mathrm{jml}$ & $\%$ & $\mathrm{jml}$ & $\%$ & jml & $\%$ \\
\hline $\begin{array}{l}\text { Saya tidak marah ketika } \\
\text { usaha orang lain lebih baik } \\
\text { dari usaha saya }\end{array}$ & 30 & 3 & 10 & 19 & 63,3 & 8 & 26,6 & 0 & 0 & 0 & 0 \\
\hline \multirow[t]{4}{*}{ jumlah } & Rata-rata & \multicolumn{10}{|l|}{3,8} \\
\hline & SD & \multicolumn{10}{|c|}{0,61} \\
\hline & modus & \multicolumn{10}{|l|}{4} \\
\hline & skor & \multicolumn{10}{|l|}{114} \\
\hline
\end{tabular}

Sumber: Data primer yang diolah tahun 2019

Dari tabel diatas terlihat dimensi empati dengan indikator Saya tidak marah ketika usaha orang lain lebih baik dari usaha saya memiliki rata-rata 3,8 dengan angka modus 4 dan standard deviasi 0,61. Dengan skor 114 Hal ini menggambarkan bahwa dimensi kesadaran diri pada responden di kategorikan Baik.

Tabel 12. Deskriptif Empati Pernyataan 3

\begin{tabular}{|c|c|c|c|c|c|c|c|c|c|c|c|}
\hline \multirow{4}{*}{$\begin{array}{l}\text { Dimensi empati } \\
\text { indikator }\end{array}$} & \multirow{4}{*}{$\begin{array}{l}\text { Jumlah } \\
\text { responden }\end{array}$} & \multicolumn{10}{|c|}{ Frekuensi jawaban responden } \\
\hline & & \multicolumn{2}{|c|}{ ss } & \multirow{2}{*}{\multicolumn{2}{|c|}{$\begin{array}{l}\mathrm{s} \\
4\end{array}$}} & \multicolumn{2}{|l|}{ ks } & \multicolumn{2}{|l|}{ ts } & \multicolumn{2}{|l|}{ sts } \\
\hline & & \multicolumn{2}{|l|}{5} & & & \multicolumn{2}{|l|}{3} & \multicolumn{2}{|l|}{2} & \multicolumn{2}{|l|}{1} \\
\hline & & jml & $\%$ & jml & $\%$ & $\mathrm{jml}$ & $\%$ & $\mathrm{jml}$ & $\%$ & jml & $\%$ \\
\hline $\begin{array}{l}\text { Saya senang ketika mendapat } \\
\text { saran untuk kepentingan } \\
\text { usaha sewa lapangan futsal }\end{array}$ & 30 & 4 & 13,3 & 20 & 66,6 & 6 & 20 & 0 & 0 & 0 & 0 \\
\hline \multirow[t]{4}{*}{ jumlah } & Rata-rata & \multicolumn{10}{|c|}{3,93} \\
\hline & SD & \multicolumn{10}{|c|}{0,58} \\
\hline & modus & \multicolumn{10}{|l|}{4} \\
\hline & skor & \multicolumn{10}{|l|}{118} \\
\hline
\end{tabular}

Sumber: Data primer yang diolah tahun 2019

Dari tabel diatas terlihat dimensi empati dengan indikator Saya tidak marah ketika usaha orang lain lebih baik dari usaha saya memiliki rata-rata 3,8 dengan angka modus 4 dan standard deviasi 0,61. Dengan skor 118 Hal ini menggambarkan bahwa dimensi kesadaran diri pada responden di kategorikan Baik.

\section{Ketrampilan sosial}

Tabel 13. Deskriptif Dimensi Ketrampilan Social Pernyataan 1

\begin{tabular}{|c|c|c|c|c|c|c|c|c|c|c|c|}
\hline \multirow[t]{2}{*}{ Dimensi ketrampilan sosial } & \multirow{4}{*}{$\begin{array}{l}\text { Jumlah } \\
\text { responden }\end{array}$} & \multicolumn{10}{|c|}{ Frekuensi jawaban responden } \\
\hline & & \multirow{2}{*}{\multicolumn{2}{|c|}{$\begin{array}{ll}\text { SS } \\
5\end{array}$}} & \multirow{2}{*}{\multicolumn{2}{|c|}{\begin{tabular}{|l|}
$s$ \\
4
\end{tabular}}} & \multicolumn{2}{|l|}{$\mathrm{ks}$} & \multirow{2}{*}{\multicolumn{2}{|c|}{\begin{tabular}{|l|} 
ts \\
2
\end{tabular}}} & \multirow{2}{*}{\multicolumn{2}{|c|}{$\begin{array}{l}\text { sts } \\
1\end{array}$}} \\
\hline \multirow{2}{*}{ indikator } & & & & & & 3 & & & & & \\
\hline & & $\mathrm{jml}$ & $\%$ & $\mathrm{jml}$ & $\%$ & $\mathrm{jml}$ & $\%$ & $\mathrm{jml}$ & $\%$ & $\mathrm{jml}$ & $\%$ \\
\hline $\begin{array}{l}\text { Saya tidak malu meminta } \\
\text { bantuan teman ketika terjadi } \\
\text { masalah dengan usaha sewa } \\
\text { lapangan futsal saya }\end{array}$ & 30 & 6 & 20 & 17 & 56,6 & 7 & 23,3 & 0 & 0 & 0 & 0 \\
\hline \multirow[t]{4}{*}{ jumlah } & Rata-rata & \multicolumn{10}{|c|}{3,96} \\
\hline & SD & \multicolumn{10}{|c|}{0,66} \\
\hline & modus & \multicolumn{10}{|l|}{4} \\
\hline & skor & \multicolumn{10}{|c|}{119} \\
\hline
\end{tabular}

Sumber: Data primer yang diolah tahun 2019 
Dari tabel diatas terlihat dimensi empati dengan indikator Saya tidak malu meminta bantuan teman ketika terjadi masalah dengan usaha sewa lapangan futsal saya memiliki rata-rata 3,96 dengan angka modus 4 dan standard deviasi 0,66. Dengan skor 119 Hal ini menggambarkan bahwa dimensi kesadaran diri pada responden di kategorikan Baik.

Tabel 14. Deskriptif Dimensi Ketrampilan Social Pernyataan 2

\begin{tabular}{|c|c|c|c|c|c|c|c|c|c|c|c|}
\hline \multirow[t]{2}{*}{ Dimensi ketrampilan sosial } & \multirow{4}{*}{$\begin{array}{l}\text { Jumlah } \\
\text { responden }\end{array}$} & \multicolumn{10}{|c|}{ Frekuensi jawaban responden } \\
\hline & & \multicolumn{2}{|l|}{ Ss } & \multicolumn{2}{|l|}{$\mathrm{s}$} & \multicolumn{2}{|l|}{ ks } & \multirow{2}{*}{\multicolumn{2}{|c|}{$\frac{\text { ts }}{2}$}} & \multirow{2}{*}{\multicolumn{2}{|c|}{$\begin{array}{l}\text { sts } \\
1\end{array}$}} \\
\hline \multirow[t]{2}{*}{ indikator } & & \multicolumn{2}{|l|}{5} & \multicolumn{2}{|l|}{4} & \multicolumn{2}{|l|}{3} & & 2 & & \\
\hline & & jml & $\%$ & $\mathrm{jml}$ & $\%$ & jml & $\%$ & jml & $\%$ & $\mathrm{jml}$ & $\%$ \\
\hline $\begin{array}{l}\text { Saya tidak malu } \\
\text { mempromosikan usaha sewa } \\
\text { lapangan futsal saya }\end{array}$ & 30 & 7 & 23,3 & 17 & 56,6 & 6 & 20 & 0 & 0 & 0 & 0 \\
\hline \multirow[t]{4}{*}{ jumlah } & Rata-rata & \multicolumn{10}{|c|}{4,03} \\
\hline & SD & \multicolumn{10}{|c|}{0,66} \\
\hline & modus & \multicolumn{10}{|c|}{4} \\
\hline & skor & \multicolumn{10}{|c|}{121} \\
\hline
\end{tabular}

Sumber: Data primer yang diolah tahun 2019

Dari tabel diatas terlihat dimensi empati dengan indikator Saya tidak malu mempromosikan usaha sewa lapangan futsal saya memiliki rata-rata 4,03 dengan angka modus 4 dan standard deviasi 0,66. Dengan skor $121 \mathrm{Hal}$ ini menggambarkan bahwa dimensi kesadaran diri pada responden di kategorikan Sangat Baik.

\section{Pembahasan}

Dari Hasil penjelasan pengolaan penyebaran kuisioner di atas yang terbagi menjadi lima indikator pernyataan yaitu kesadaran diri,pengaturan diri,motivasi,empati dan ketrampilan sosial,yang mana satu indikator terbagi lagi masing-masing tiga butir pernyataan dan sudah saya bahas. berikut adalah tabel rekapan dari semua tabel yang saya bahas :

Tabel 16. Rekapan Hasil

\begin{tabular}{|l|c|c|}
\hline \multicolumn{1}{|c|}{ INDIKATOR } & $\begin{array}{c}\text { RATA-RATA } \\
\text { SKOR }\end{array}$ & KATEGORI \\
\hline Kesadaran Diri & 115 & Baik \\
\hline Pengaturan Diri & 111 & Baik \\
\hline Motivasi & 128,6 & Sangat Baik \\
\hline Empati & 116,3 & Baik \\
\hline Ketrampilan Sosial & 118,3 & Baik \\
\hline
\end{tabular}

Dari hasil Rekapan Tabel di atas Peneliti dapat Menyimpulkan bahwa dari kelima Faktor yaitu kesadaran diri,pengaturan diri,motivasi,empati dan ketrampilan sosial yang menjadi Faktor yang paling Memotivasi Masyarakat Berwirausaha Sewa Lapangan Futsal di Kota Jambi adalah Fakor Motivasi dengan skor rata-rata 128,6 yang di kategorikan Sangat Baik.

Hasil penelitian ini sejalan dengan penelitian-penelitian terdahulu yang menyimpulkan bahwa kesadaran diri, penaturn diri, motivasi, empati dan keterampilan social mempengaruhi minat berwirausaha (Hermansyah, H., \& Dahmiri, D., 2019; Afif Nur Rahmadi dan Budi Heryanto., 2016; Dassaad dan Abdurrahman Adi Sukma. 2012, Winda Safitri, Dahmiri., 2019). 


\section{SIMPULAN DAN SARAN}

\section{Simpulan}

1. Ada beberapa faktor yang membuat masyarakat terdorong untuk melakukan wirausaha yaitu,faktor kesadaran diri,pengaturan diri,motivasi,empati dan ketrampilan sosial.

2. Faktor motivasi di kategorikan sangat baik karena menjadi faktor yang paling mempengaruhi masyarakat untuk berwirausaha sewa lapangan futsal di kota jambi.

\section{Saran}

Dari kelima Faktor yang di bahas,Pengaturan Diri menjadi Faktor yang paling lemah di pilih oleh responden dengan butir pernyataan adalah "Saya berusaha mempersiapkan diri untuk menghadapi kemungkinan terjadi terhadap usaha sewa lapanngan futsal saya " .

Menurut Saya para pelaku usaha sewa lapangan futsal harus siap dengan segala kemungkinan yang akan terjadi dengan usaha mereka,Karena dalam dunia usaha masalah sudah biasa tejadi, tinggal sebagai pelaku usahanya siap atau tidak menghadapinya. Adapun masukan dari peneliti apabila masalah terjadi terhadap usaha adalah yang pertama tenangkan pikiran,pikiran yang tenang akan membuat diri lebih nyaman dan tidak bertindak tergesa-gesa,Kemudian gunakan cara berpikir kreatif untuk menemukan solusi masalah yang terjadi pada usaha, Mintalah pertolongan Tuhan yang maha esa,karena sesungguhnya murah atau tidaknya rezeki sudah di atur olehnya, dan yang terakhir adalah jangan putus asa, anggaplah masalah adalah awal kesuksesan dari usaha.

\section{DAFTAR PUSTAKA}

Afif Nur Rahmadi dan Budi Heryanto. 2016. Analisis Faktor-faktor yang Mempengaruhi Minat Berwirausaha Pada Mahasiswa Program Studi Manajemen Fakultas Ekonomi Universitas Kadiri. Vol.1 No.2 September 2016, pp.153-169.

Alma, Buchari. 2011. Kewirausahaan Untuk Mahasiswa dan Umum, Bandung: Alfabeta Almahdi, Z. (2008) Bisnis futsal. Yogyakarta: Ayyana Mangunegara.

April eni suryani( (2016),pengaruh kualitas pelayanan,lokasi dan harga terhadap keputusan menyewa jasa lapangan futsal mensana kota kendiri:universitas negri Yogyakarta

Augusty, Ferdinand. 2006. Metode Penelitian Manajemen: Pedoman Penelitian untuk skripsi, Tesis dan Disertai Ilmu Manajemen. Semarang: Universitas Diponegoro

Basu, Swasta DH dan Irawan. 2001. Manajemen Pemasaran Modern. YogyakartaLiberty

Bilson Simamora, 2002, Panduan Riset Perilaku Konsumen, Surabaya: Pustaka Utama

Hermansyah, H., \& Dahmiri, D. (2019). Analisis Faktor-Faktor Yang Mempengaruhi Keberhasilan Berwirausaha Industri Percetakan (Studi Kasus Wirausaha Industri Percetakan Di Kota Jambi). Jurnal Manajemen Terapan dan Keuangan, 8(3),38-44.

Dassaad dan Abdurrahman Adi Sukma. 2012. Faktor-faktor yang Mempengaruhi Minat

Mahasiswa untuk Berwirausaha. Skripsi. Fakultas Ekonomi Universitas Guna

Dharma .

John D. Tenang. 2008. Mahir Bermain Futsal. Jakarta : Mizan

Kasmir. 2010. Kewirausahaan. Jakarta: PT Raja Grafindo Persada

Kuncara (2008:1) faktor pendorong kewirausahaan terdiri atas faktor internal dan faktor eksternal. 
Lieli Suharti dan Hanisirine. (2011) Faktor-faktor yang Berpengaruh Terhadap Niat Kewirausahaan (Entrepreneur Intention). Jurnal Manajemen dan Kewirausahaan Machfoedz,Mas ${ }^{e e}$ de dan Machfoedz, Mahmud. 2005. Kewirausahaan (Metode,Manajemen, \& Implementasi) BPPE : Yogyakarta

Wikipedia (2018) Karaktristik Futsal. Tersedia di: http://id.wikipedia.org/wiki/Futsal. [Diakses 20 April 2018].

Winardi,J. 2002. Motivasi dan Pemotivasian dalam manajemen. Raja Grafindo Persada : Jakarta

Winda Safitri, Dahmiri. (2019). Pengaruh Faktor Internal Terhadap Minat Berwirausaha Mahasiswa Fakultas Ekonomi Dan Bisnis Universitas Jambi. Jurnal Manajemen Terapan Dan Keuangan, Vol. 8. No. 1 April 2019.

Zimmerer, W.T. 2002.Essentials of Entrepreneurship and Small Business Management.Third Edition. New york: Prentice-HallS 